\title{
The effect of potassium on photosynthetic acclimation in cucumber during $\mathrm{CO}_{2}$ enrichment
}

\author{
X. DABU*, S. LI*, Z. CAI*, T. GE*, and M. HAI**+, \\ College of Resources and Environment of Yunnan Agricultural University, Yunnan Agricultural University in \\ Panlong District, Kunming, Yunnan Province, China* \\ College of Agronomy and Biotechnology of Yunnan Agricultural University, Yunnan Agricultural University in \\ Panlong District, Kunming, Yunnan Province, China**
}

\begin{abstract}
Long-term $\mathrm{CO}_{2}$ enrichment $\left(1,000 \mu \mathrm{mol} \mathrm{mol}^{-1}\right)$ leads to photosynthetic acclimation in cucumber. Here, through hydroponic experiments in an open-top climate chamber system, we investigated key photosynthetic parameters of cucumbers using potassium stimulation (120 or $240 \mathrm{mg} \mathrm{L}^{-1}$ ). Short-term $\mathrm{CO}_{2}$ enrichment (less than 25 days) significantly increased the net photosynthetic rate in cucumber. However, long-term $\mathrm{CO}_{2}$ enrichment $(43 \mathrm{~d})$ led to photosynthetic acclimation and decrease in stomatal conductance. The increase in potassium alleviated the decrease in photosynthetic rate and stomatal conductance, which reduced photosynthetic acclimation. In addition, ${ }^{13} \mathrm{C}$ isotope tracing showed that under $\mathrm{CO}_{2}$ enrichment, plants with higher potassium concentrations showed higher sink/source and flow/source ratios of photosynthetic assimilative $\mathrm{C}$ $\left(\delta^{13} \mathrm{C}\right)$ abundance. Moreover, the abnormal accumulation of soluble carbohydrates and starch resulted in photosynthetic acclimation in cucumber. Increasing potassium significantly reduced the accumulation of soluble carbohydrates and promoted the transport of soluble carbohydrates to the sink, which alleviated photosynthetic acclimation.
\end{abstract}

Additional key words: $\mathrm{CO}_{2}$ enrichment; cucumber; final product negative feedback; photosynthetic acclimation; potassium.

\section{Introduction}

Changes in photosynthesis in response to high atmospheric $\mathrm{CO}_{2}$ concentrations vary with exposure time. Changes due to a short-term exposure (a few minutes to a few days) is usually referred to as a response, whereas those due to long-term exposure (a few weeks to a few months) are usually described as acclimation. Short-term enriched $\mathrm{CO}_{2}$ exposure increases photosynthetic rate. However, long-term high $\mathrm{CO}_{2}$ exposure (albeit periodically) gradually reduces the photosynthetic rate of leaves and eventually leads to a lower photosynthetic rate compared to that observed under regular $\mathrm{CO}_{2}$ concentrations. This phenomenon is defined as photosynthetic acclimation or downregulation. $\mathrm{CO}_{2}$ enrichment results in an increase in carbohydrates in plants, particularly in leaves (Kimball et al. 2002). The massive accumulation of carbohydrates under long-term $\mathrm{CO}_{2}$ enrichment results in a negative feedback to photosynthesis, which leads to a reduction in the photosynthetic rate and photosynthetic acclimation (Delucia et al. 1985). Most of the recent studies on the negative feedback mechanism of photosynthetic acclimation were based on free-air $\mathrm{CO}_{2}$ enriched (FACE) conditions, namely continuous $\mathrm{CO}_{2}$ enrichment within a concentration range of 500-700 $\mu \mathrm{mol} \mathrm{mol}{ }^{-1}$. Studies on photosynthetic acclimation and its negative feedback mechanism under $\mathrm{CO}_{2}$ fertilization conditions (at least $1,000 \mu \mathrm{mol} \mathrm{mol}{ }^{-1}$, periodically) are limited. In greenhouses, an increase in photosynthetic activity, which occurs at 2-3 h after sunrise, reduces $\mathrm{CO}_{2}$ concentrations below $100 \mu \mathrm{mol}$ $\mathrm{mol}^{-1}$ that in turn limits the growth of crops due to severe $\mathrm{CO}_{2}$ deficiency and subsequent photosynthesis suspension (Maggio et al. 2002). Therefore, $\mathrm{CO}_{2}$ fertilization has been widely applied. A study has shown that the optimal $\mathrm{CO}_{2}$ enrichment concentration is $1,200 \mu \mathrm{mol} \mathrm{mol}{ }^{-1}$, and the optimal period is $25 \mathrm{~d}$ in periodic administration (Lin et al. 2011).

Potassium promotes the transport of photosynthetic products to storage organs. In this study, using cucumber as the experimental plant, we investigated whether the accumulation of photosynthetic products in the leaves leads to a negative feedback on photosynthesis in plants that were treated with long-term $\mathrm{CO}_{2}$ enrichment. Moreover, we evaluated the role of potassium on the transport of accumulated photosynthetic products in cucumber leaves, and whether potassium treatment alleviates photosynthetic acclimation.

Received 5 December 2017, accepted 23 April 2018.

${ }^{+}$Corresponding author; e-mail: 2250029499@qq.com

Abbreviations: $\mathrm{AC}$ - ambient $\mathrm{CO}_{2}$ concentration; DAE - days of $\mathrm{CO}_{2}$ enrichment; $\mathrm{EC}$ - elevated $\mathrm{CO}_{2}$ concentration; FACE - free-air $\mathrm{CO}_{2}$ enriched; HPLC - high-performance liquid chromatography; $\mathrm{g}_{\mathrm{S}}-$ stomatal conductance; $P_{\mathrm{N}}-$ net photosynthetic rate.

Acknowledgments: The National Natural Science Foundation (grant number 31360499) supported this study. We thank the Chinese Academy of Sciences, Institute of Botany, State Key Laboratory of Vegetation and Environmental Change for performing C isotope analysis. We thank Yunnan Yunce Quality Testing Co., Ltd. for conducted HPLC analysis of photosynthetic products. 


\section{Materials and methods}

Locations and materials: The experiment was performed at the farm greenhouse of the Yunnan Agriculture University. The two open-top, plastic film culture chambers inside the greenhouse were $5 \mathrm{~m}$ in length, $1.5 \mathrm{~m}$ in width, and $1.5 \mathrm{~m}$ in height. The experimental cucumber (Cucumis sativus L.) cultivar was Zhongnong 20 (from the Institute of Vegetables and Flowers at the Chinese Academy of Agricultural Sciences). The indoor $\mathrm{CO}_{2}$ concentration was measured using an infrared carbon dioxide detector (Telaire7001, Telaire, USA). The chamber was supplied with $\mathrm{CO}_{2}(99.9 \%$ purity) from a high-pressure steel cylinder after buffering.

Experimental design and protocol: Four groups were used in the experiment. Plants were treated with two different $\mathrm{CO}_{2}$ concentrations: the control (AC, $380 \mu \mathrm{mol}$ $\mathrm{mol}^{-1}$ ) and the $\mathrm{CO}_{2}$ enrichment (EC, 1,000 $\left.\mu \mathrm{mol} \mathrm{mol}^{-1}\right)$. At each $\mathrm{CO}_{2}$ concentration, plants were further treated with two different potassium concentrations [120 (K120) and 240 (K240) $\mathrm{mg} \mathrm{L}^{-1}$. For each treatment, nine replicates were performed. A total of 36 plants were studied.

Modified Hoagland medium was used in the experiment. The ingredients were as follows: 261.39 $\mathrm{g}\left(\mathrm{K}_{2} \mathrm{SO}_{4}\right) \mathrm{L}^{-1} ; 5.22 \mathrm{~g}(\mathrm{KCl}) \mathrm{L}^{-1} ; 295 \mathrm{~g}\left(\mathrm{Ca}\left(\mathrm{NO}_{3}\right)_{2} \cdot 4 \mathrm{H}_{2} \mathrm{O}\right) \mathrm{L}^{-1}$; $35.51 \mathrm{~g}\left(\mathrm{Ca}\left(\mathrm{H}_{2} \mathrm{PO}_{4}\right)_{2} \cdot \mathrm{H}_{2} \mathrm{O}\right) \mathrm{L}^{-1} ; 42.11 \mathrm{~g}(\mathrm{EDTA}-\mathrm{Na}-\mathrm{Fe}) \mathrm{L}^{-1}$; $160.21 \mathrm{~g}\left(\mathrm{MgSO}_{4} \cdot 7 \mathrm{H}_{2} \mathrm{O}\right) \mathrm{L}^{-1} ; 0.3905 \mathrm{~g}\left(\mathrm{MnSO}_{4} \cdot \mathrm{H}_{2} \mathrm{O}\right) \mathrm{L}^{-1}$; $0.0555 \mathrm{~g}\left(\mathrm{ZnSO}_{4} \cdot 7 \mathrm{H}_{2} \mathrm{O}\right) \mathrm{L}^{-1} ; 0.0206 \mathrm{~g}\left(\mathrm{CuSO}_{4} \cdot 5 \mathrm{H}_{2} \mathrm{O}\right) \mathrm{L}^{-1}$; $0.725 \mathrm{~g}\left(\mathrm{H}_{3} \mathrm{BO}_{3}\right) \mathrm{L}^{-1}$; and $0.0046 \mathrm{~g}\left(\left(\mathrm{NH}_{4}\right)_{6} \mathrm{Mo}_{7} \mathrm{O}_{24} \cdot 4 \mathrm{H}_{2} \mathrm{O}\right)$ $\mathrm{L}^{-1}$. A $1 / 4$-ion strength Hoagland nutrient solution was prepared by diluting the original medium by 1,000 times.

On 5 March 2016, seeds were germinated in a $25^{\circ} \mathrm{C}$ incubator with daily morning and night watering. After $48 \mathrm{~h}$, the germinated seeds were planted in culture dishes filled with vermiculite and grown at $25^{\circ} \mathrm{C}$. When the plants exhibited three true leaves ( 27 March), they were transplanted to culture dishes filled with water for one week. On 3 April, 1/4-ion strength Hoagland medium was used to replace the water in the culture dishes, and the $\mathrm{pH}$ of the medium was adjusted to 6 using $1 \mathrm{~N}$ sulfuric acid. When the plants exhibited six true leaves (28 April), $1 / 2$-ion strength Hoagland medium was used as the culture medium. Young plants of the same size were collected and planted in plastic pots containing $3 \mathrm{~L}$ of the culture medium. Each pot contained one plant, with $24-\mathrm{h}$ ventilation and the nutrient medium was replaced every three days. Young plants of the same size were collected and separated into two $\mathrm{CO}_{2}$ chambers under the following conditions: (1) ventilated with regular air $\left(\mathrm{AC}, \mathrm{CO}_{2}\right.$ concentration of $380 \mu \mathrm{mol} \mathrm{mol}{ }^{-1}$ ); (2) ventilated with $\mathrm{CO}_{2}$ enriched air (EC, $\mathrm{CO}_{2}$ concentration of $1,000 \mu \mathrm{mol} \mathrm{mol}^{-1}$ ).

The $\mathrm{CO}_{2}$ enrichment was made in the morning from 8:00 to 12:00 h. On 4 May 2016, $\mathrm{CO}_{2}$ enrichment was started; photosynthetic characteristics were measured after 9, 25, and $43 \mathrm{~d}$ of $\mathrm{CO}_{2}$ enrichment (DAE). Samples were also collected at the same time points to evaluate the content of soluble carbohydrates and starch. ${ }^{13} \mathrm{C}$ labeling was performed on 7, 23, and 41 DAE. Approximately $48 \mathrm{~h}$ after labeling, namely at 9, 25, and 43 DAE, samples were collected for analysis using the methods demonstrated below.

Photosynthetic rate: The third functional leaf on the top of the plant was collected to evaluate photosynthetic parameters. An open-circuit photosynthetic air analysis system $L i-6400$ ( $L i-C O R$, USA) was used to measure the net photosynthetic rate $\left(P_{\mathrm{N}}\right)$ and stomatal conductance $\left(g_{\mathrm{s}}\right)$ between 9:00-11:00 $\mathrm{h}$ in each chamber.

Photosynthetic product contents: Soluble carbohydrates were measured using high-performance liquid chromatography (HPLC). The chromatographer was from Waters Corp., (USA), the detector was an evaporative light detector (e2695). The specific chromatographic conditions were as follows; column: Ca column; mobile phase: ultrapure water; flow rate: $0.6 \mathrm{~mL} \mathrm{~min}{ }^{-1}$; column temperature: $75^{\circ} \mathrm{C}$; sample injection volume: $10 \mu \mathrm{L}$ per sample. The standards for fructose, glucose, and sucrose were purchased from Amersoc. The stachyose standard was purchased from Sigma. The soluble carbohydrates discussed in this study included fructose, glucose, sucrose, and stachyose.

The measuring method was performed according to Qi et al. (2006) and Yu (1985). Briefly, at the indicated time points, three samples from the leaves, stems, roots, and fruits of each plant were collected and stored in a $-60^{\circ} \mathrm{C}$ freezer for further analysis. Approximately $0.3 \mathrm{~g}$ of frozen samples was ground and extracted using $50 \mathrm{~mL}$ of extraction buffer (99\% ethanol). After $10 \mathrm{~min}$ of homogenization, the samples were centrifuged at $5,000 \times g$ for $15 \mathrm{~min}$, and the supernatants were collected. The extraction, homogenization, and centrifugation processes were repeated thrice, and supernatants from each sample were pooled. The combined supernatants were then dried through reduced pressure evaporation at $40^{\circ} \mathrm{C}$. The dried mass was dissolved in $15 \mathrm{~mL}$ of deionized water. Five milliliters of chloroform was then added to the solution followed by oscillation, centrifugation, and organic phase removal. This purification process was repeated thrice to remove the phospholipids in the extracts. The $\mathrm{pH}$ of the remaining water phase was adjusted to 7 using $0.1 \mathrm{M} \mathrm{NaOH}$, and the solution was dried using a rotary evaporator at $40^{\circ} \mathrm{C}$. The dried mass was dissolved using $500 \mu \mathrm{L}$ of deionized water and then filtered using a $0.45-\mu \mathrm{m}$ syringe filter prior to analysis.

The extraction and measurement of starch was performed as follows: approximately $2.5 \mathrm{~g}$ of the sample was added to a $250-\mathrm{mL}$ round bottom flask and incubated with $80 \%$ ethanol overnight. The sample was refluxed in a reflux condenser for $1 \mathrm{~h}$ to remove soluble carbohydrates. The remaining biomass was dried at $60^{\circ} \mathrm{C}$ until no ethanol could be detected and then transferred to another $250-\mathrm{mL}$ round bottom flask. The sample was refluxed and hydrolyzed in the presence of $70 \mathrm{~mL}$ of water and $7 \mathrm{~mL}$ of hydrochloric acid for $2.5 \mathrm{~h}$ in a boiling water bath. The hydrolyzed sample was filtered and then transferred to a $10-\mathrm{mL}$ volumetric flask. One drop of methyl red indicator $\left(5 \mathrm{~g} \mathrm{~L}^{-1}\right)$ was added to the sample for $\mathrm{pH}$ adjustment. The $\mathrm{pH}$ value was adjusted to 7 by using $400 \mathrm{~g} \mathrm{~L}^{-1} \mathrm{NaOH}$ buffer for coarse adjustment and $10 \mathrm{~g} \mathrm{~L}^{-1} \mathrm{NaOH}$ buffer for fine 
adjustment. The sample solution was titrated to $10 \mathrm{~mL}$. Two milliliters of the sample solution was filtered using $0.45-\mu \mathrm{m}$ syringe filter, and $20 \mu \mathrm{L}$ of the filtered solution was used for analysis.

Carbon isotope tracing: The carbon isotope labeling and analysis were performed according to Yin (2010). Carbon isotope labeling was performed at 7, 23, and $41 \mathrm{DAE}$, starting at 9:00 a.m. on a sunny day. The labeling isotope was ${ }^{13} \mathrm{C}$ in $\mathrm{CO}_{2}$. Labeling time was $1 \mathrm{~h}$. While labeling, an infrared carbon dioxide detector Telaire7001 was used to monitor the concentration of $\mathrm{CO}_{2}$ to prevent overheating. Approximately $48 \mathrm{~h}$ after labeling, samples from the roots, stems, and leaves were collected and pre-treated. After labeling at all above indicated time points was completed, the abundance of isotope $\delta^{13} \mathrm{C}$ was measured using the isotope analyzer Picarro CM-CRDS (Picarro, USA).

Isotope abundance is the percentage of a specific element isotope in the total number of atoms. Usually, the carbon isotope abundance in the soil and plants is expressed as $\delta^{13} \mathrm{C}$. The formula is:

$\delta^{13} \mathrm{C}(\%)=\left(\mathrm{R}_{\text {sample }} / \mathrm{RPDB}-1\right) \times 1,000$,

where $\mathrm{R}_{\text {sample }}$ represents the isotope abundance ratio of ${ }^{13} \mathrm{C} /{ }^{12} \mathrm{C}$ in the sample; and $\mathrm{RPDB}$ or ${ }^{13} \mathrm{C} /{ }^{12} \mathrm{C}$ (PDB) represents the isotope abundance ratio of ${ }^{13} \mathrm{C} /{ }^{12} \mathrm{C}$ in the standard.

Carbon isotope abundance $\delta^{13} \mathrm{C}$ was used to measure carbon isotope content in different cucumber organs.

Biomass content: At 9, 25, and 43 DAE, samples were collected and washed with deionized water, and surface moisture was dried using absorbent paper. The root, stem, leaf, and fruit were weighed and recorded respectively. The samples were incubated at $105^{\circ} \mathrm{C}$ for $30 \mathrm{~min}$ for enzyme deactivation, followed by complete drying at $80^{\circ} \mathrm{C}$. The dry mass was weighed and recorded as the total mass of the plant.

Data analysis: One-way and double-way analysis of variance $(A N O V A)$ was applied to test difference of dates between different treatments with a $95 \%$ confidence level or $\alpha=0.05$ and a $99 \%$ confidence level or $\alpha=0.01$ and mapped by Origin 8 .

\section{Results}

Total biomass: By 43 DAE, the plants treated with AC and K240 exhibited an elevated total biomass compared to the plants treated with AC and K120 (Fig. 1). Furthermore, the total biomass of plants treated with EC and K120 was higher than that of plants treated with ambient $\mathrm{CO}_{2}$ concentration and K240 (AC-K240). The total biomass of plants treated with EC and K240 was significantly higher than that of any other groups. Our results indicated a synergism between $\mathrm{CO}_{2}$ concentration and potassium contents on increasing total cucumber biomass.

Net photosynthetic rate and stomatal conductance: From 9 to $25 \mathrm{DAE}, P_{\mathrm{N}}$ significantly increased, which coin-

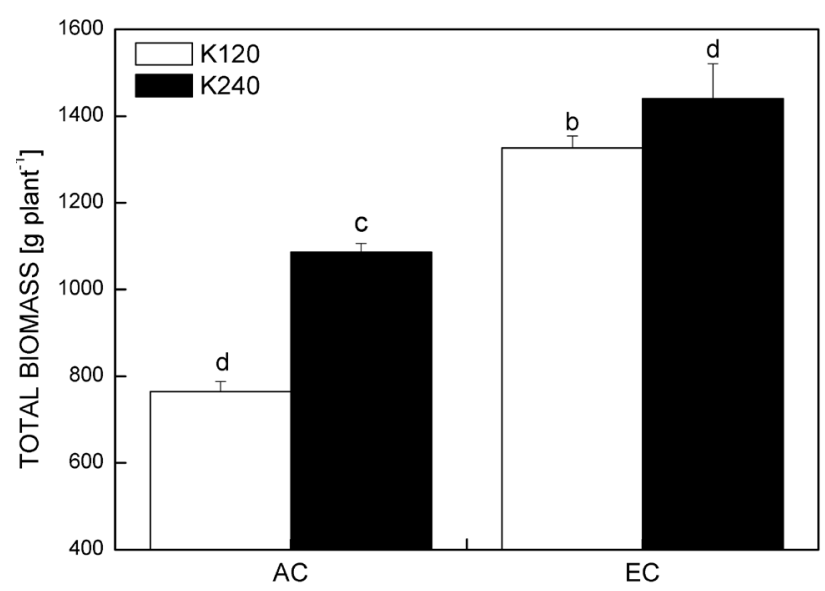

Fig. 1. Effects of elevated $\mathrm{CO}_{2}$ concentrations and increasing potassium concentrations to total biomass on cucumber plants grown in a greenhouse (95\% confidence level or $\alpha=0.05$ ). $\mathrm{AC}$ - ambient $\mathrm{CO}_{2}$ concentration $\left(380 \mu \mathrm{mol} \mathrm{mol}^{-1}\right) ; \mathrm{EC}$ - elevated $\mathrm{CO}_{2}$ concentration $\left(1,000 \mu \mathrm{mol} \mathrm{mol}^{-1}\right) ; \mathrm{K} 120$ - potassium application, $120 \mathrm{mg} \mathrm{L}^{-1}$; K240 - potassium application, $240 \mathrm{mg} \mathrm{L}^{-1}$.

cided with the observed changes in total biomass. However, by 43 DAE, photosynthetic acclimation occurred (Table 1). The plants treated with EC-K240 showed an increase in $P_{\mathrm{N}}$ compared to plants treated with EC-K120. These findings indicate that both $\mathrm{CO}_{2}$ concentrations and potassium concentrations acted synergistically in order to regulate the $P_{\mathrm{N}}$.

By 9 and 23 DAE, $g_{s}$ was mainly regulated by potassium concentrations. The $g_{\mathrm{s}}$ under K240 significantly increased compared to that of K120 (Table 2). However, by $43 \mathrm{DAE}, g_{\mathrm{s}}$ under EC significantly decreased, together with a decrease of $P_{\mathrm{N}}$. Furthermore, elevated potassium concentrations significantly alleviated the decrease in $g_{\mathrm{s}}$ and $P_{\mathrm{N}}$.

Table 1. Effects of elevated $\mathrm{CO}_{2}$ and $\mathrm{K}$ concentrations on cucumber photosynthetic rates. Results are expressed as the mean \pm standard deviation $(n=3)$. Groups with different letters represent significant differences at the same sampling time point between treatments ( $95 \%$ confidence level or $\alpha=0.05$ ). * - significant correlation, 0.05 (two-tail) confidence interval. ** - highly significant correlation, 0.01 (two-tail) confidence interval. $P_{\mathrm{N}}-$ net photosynthetic rate; $\mathrm{AC}-$ ambient $\mathrm{CO}_{2}$ concentration $\left(380 \mu \mathrm{mol} \mathrm{mol}^{-1}\right)$; EC - elevated $\mathrm{CO}_{2}$ concentration $\left(1,000 \mu \mathrm{mol} \mathrm{mol}{ }^{-1}\right) ; \mathrm{K} 120$ - potassium application, $120 \mathrm{mg} \mathrm{L}^{-1}$; $\mathrm{K} 240$ - potassium application, $240 \mathrm{mg} \mathrm{L}^{-1}$.

\begin{tabular}{llll}
\hline \multirow{2}{*}{ Treatment } & \multicolumn{2}{l}{$P_{\mathrm{N}}\left[\mu \mathrm{mol} \mathrm{m}^{-2} \mathrm{~s}^{-1}\right]$} \\
& Day 9 & Day 25 & Day 43 \\
\hline $\mathrm{AC}-\mathrm{K} 120$ & $13.514 \pm 0.859^{\mathrm{c}}$ & $12.288 \pm 1.45^{\mathrm{d}}$ & $16.716 \pm 0.934^{\mathrm{b}}$ \\
$\mathrm{AC}-\mathrm{K} 240$ & $15.431 \pm 0.989^{\mathrm{c}}$ & $16.085 \pm 0.856^{\mathrm{c}}$ & $19.609 \pm 0.592^{\mathrm{a}}$ \\
$\mathrm{EC}-\mathrm{K} 120$ & $21.729 \pm 1.544^{\mathrm{b}}$ & $24.809 \pm 0.834^{\mathrm{b}}$ & $10.821 \pm 1.094^{\mathrm{c}}$ \\
$\mathrm{EC}-\mathrm{K} 240$ & $25.471 \pm 0.378^{\mathrm{a}}$ & $28.191 \pm 0.628^{\mathrm{a}}$ & $15.025 \pm 1.013^{\mathrm{b}}$ \\
$\mathrm{CO}_{2}$ & $* *$ & $* *$ & $* *$ \\
$\mathrm{~K}$ & $* *$ & $* *$ & $* *$ \\
$\mathrm{CO}_{2} * \mathrm{~K}$ & $*$ & $* *$ & $* *$ \\
\hline
\end{tabular}


Table 2. Effect of $\mathrm{CO}_{2}$ and potassium concentrations on the stomatal conductance in cucumber leaves. Results are expressed as the mean \pm standard deviation $(n=3)$. Groups with different letters represent significant differences at the same sampling time point between treatments $(95 \%$ confidence level or $\alpha=0.05)$. * - significant correlation, 0.05 (two-tail) confidence interval. ** - highly significant correlation, 0.01 (two-tail) confidence interval. $g_{\mathrm{S}}-$ stomatal conductance; $\mathrm{AC}-$ ambient $\mathrm{CO}_{2}$ concentration $\left(380 \mu \mathrm{mol} \mathrm{mol}^{-1}\right) ; \mathrm{EC}$ - elevated $\mathrm{CO}_{2}$ concentration $\left(1,000 \mu \mathrm{mol} \mathrm{mol}^{-1}\right) ; \mathrm{K} 120$ - potassium application, $120 \mathrm{mg} \mathrm{L}^{-1}$; $\mathrm{K} 240$ - potassium application, $240 \mathrm{mg} \mathrm{L}^{-1}$.

\begin{tabular}{llll} 
Treatment & \multicolumn{2}{l}{$g_{\mathrm{s}}\left[\mu \mathrm{mol} \mathrm{m}^{-2} \mathrm{~s}^{-1}\right]$} \\
& Day 9 & Day 25 & Day 43 \\
\hline AC-K120 & $0.67 \pm 0.02^{\mathrm{b}}$ & $0.56 \pm 0.06^{\mathrm{b}}$ & $0.58 \pm 0.16^{\mathrm{b}}$ \\
$\mathrm{AC}-\mathrm{K} 240$ & $0.82 \pm 0.03^{\mathrm{a}}$ & $0.65 \pm 0.08^{\mathrm{a}}$ & $0.7 \pm 0.13^{\mathrm{a}}$ \\
$\mathrm{EC}-\mathrm{K} 120$ & $0.62 \pm 0.1^{\mathrm{b}}$ & $0.52 \pm 0.08^{\mathrm{b}}$ & $0.15 \pm 0.04^{\mathrm{d}}$ \\
$\mathrm{EC}-\mathrm{K} 240$ & $0.78 \pm 0.01^{\mathrm{a}}$ & $0.57 \pm 0.16^{\mathrm{a}}$ & $0.37 \pm 0.1^{\mathrm{c}}$ \\
$\mathrm{CO}_{2}$ & $\mathrm{~ns}$ & $\mathrm{~ns}$ & $\mathrm{~ns}$ \\
$\mathrm{~K}$ & $*$ & $*$ & $* *$ \\
$\mathrm{CO}_{2} * \mathrm{~K}$ & $\mathrm{~ns}$ & $\mathrm{~ns}$ & $*$
\end{tabular}

Distribution of photosynthetic assimilative products ( ${ }^{13} \mathbf{C}$ tracing): By 9, 25, and $43 \mathrm{DAE}$, the accumulation of photosynthetic assimilative $\mathrm{C}\left(\delta^{13} \mathrm{C}\right)$ was highly significantly elevated in the roots in K240 compared to K120 (Fig. 2). The accumulation of $\delta^{13} \mathrm{C}$ also significantly increased in the stems and leaves, as demonstrated in the same tracing assays. By 9 DAE, K240 increased the accumulation of photosynthetic assimilative $\mathrm{C}$ by $5,636.7,52.7$, and $51.7 \%$ in the roots, stems, and leaves, respectively, compared to that in plants treated with K120. By 25 DAE, the increase changed to $620.2,55.0$, and $64.7 \%$, respectively. By 43 DAE, the increase changed to $823.6,113.8$, and $49.7 \%$, respectively. A significant difference in accumulation between K120 and K240 was observed in the stems and leaves and a highly significant difference was observed in the roots.

The effect of $\mathrm{CO}_{2}$ enrichment and high potassium concentrations on the sink (root)/source (leaf) ratio and the flow (stem)/source (leaf) ratio of $\delta^{13} \mathrm{C}$ abundance is shown in Table 3. After EC, the sink/source ratio and flow/source ratio of $\delta^{13} \mathrm{C}$ at $\mathrm{K} 240$ was higher than that of $\delta^{13} \mathrm{C}$ at $\mathrm{K} 120$. In addition, the sink/source ratio and flow/source ratio of $\delta^{13} \mathrm{C}$ in plants treated with $\mathrm{K} 240$ increased at the three time points tested, particularly by 25 and 43 DAE.

Accumulation of photosynthetic assimilative products (starch and soluble carbohydrates): The plants treated with EC-K240 exhibited a higher root/leaf ratio of soluble carbohydrate content compared to the other groups (Table 4). The plants treated with EC-K240 exhibited a lower root/leaf starch content ratio compared to the other groups (Table 5).

Correlation analysis between $P_{\mathrm{N}}$ and the content of soluble carbohydrates and starch: The four groups exhibited a negative correlation between $P_{\mathrm{N}}$ and starch

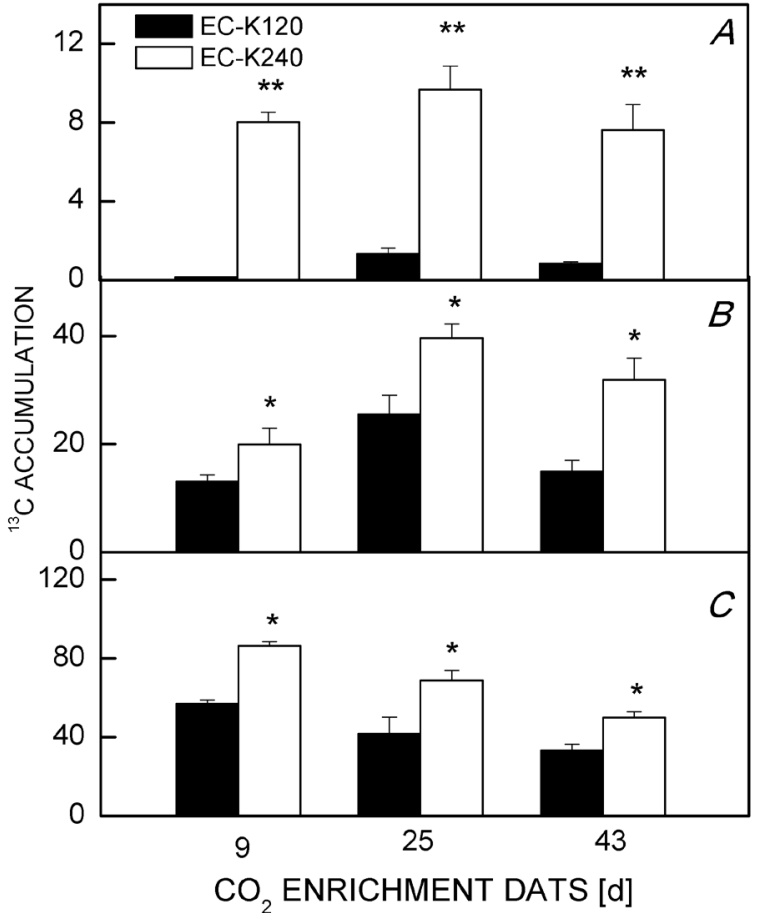

Fig. 2. Effects of various potassium concentrations and high $\mathrm{CO}_{2}$ concentrations on $\mathrm{C}\left(\delta^{13} \mathrm{C}\right)$ accumulation in the roots, stems, and leaves of cucumber plants. *Significant correlation, 0.05 (two-tail) confidence interval. **Highly significant correlation, 0.01 (two-tail) confidence interval. $\mathrm{AC}-$ ambient $\mathrm{CO}_{2}$ concentration $\left(380 \mu \mathrm{mol} \mathrm{mol}{ }^{-1}\right)$; EC - elevated $\mathrm{CO}_{2}$ concentration $\left(1,000 \mu \mathrm{mol} \mathrm{mol}{ }^{-1}\right) ; \mathrm{K} 120$ - potassium application, $120 \mathrm{mg} \mathrm{L}^{-1}$; $\mathrm{K} 240$ - potassium application, $240 \mathrm{mg} \mathrm{L}^{-1}$.

content. The plants treated with EC and K240 exhibited a highly significant, negative correlation between $P_{\mathrm{N}}$ and starch content (Table 6).

\section{Discussion}

$\mathrm{CO}_{2}$ is the main component of dry mass in plants and it has been widely reported that $\mathrm{CO}_{2}$ enrichment increases plant biomass. For example, Agüera et al. (2006) showed that $\mathrm{CO}_{2}$ enrichment increases the total biomass of cucumber plants. Using elevated $\mathrm{CO}_{2}$ and potassium conditions in cotton, Reddy et al. (2005) showed that increasing potassium contents in the soil promotes dry mass accumulation in plants, which acts synergistically with higher $\mathrm{CO}_{2}$ concentrations. In the present study, we showed that $\mathrm{CO}_{2}$ enrichment increased the biomass of cucumber, and the increase in potassium contents further elevated the total biomass of cucumber. Thus, we conclude that $\mathrm{CO}_{2}$ acted synergistically with potassium and increased cucumber biomass.

Short-term (several days) $\mathrm{CO}_{2}$ enrichment increases the photosynthetic capability of plants, which was reflected in the present study by an increase in $P_{\mathrm{N}}$ and $g_{\mathrm{s}}$. However, long-term (several weeks) $\mathrm{CO}_{2}$ enrichment induces different responses in plants (Long et al. 2004). Studies on photosynthetic acclimation under FACE conditions have been developed, whereas investigations on $\mathrm{CO}_{2}$ fertilization conditions (high concentration, periodic administration) 
Table 3. The effect of $\mathrm{CO}_{2}$ and potassium on the ratio of $\mathrm{C}$ abundance $\left(\delta^{13} \mathrm{C}\right)$ sink (root)/source (leaf), flow (stem)/source (leaf) ratio to cucumber. $\mathrm{AC}-$ ambient $\mathrm{CO}_{2}$ concentration (380 $\left.\mu \mathrm{mol} \mathrm{mol}{ }^{-1}\right)$; EC - elevated $\mathrm{CO}_{2}$ concentration $(1,000 \mu \mathrm{mol}$ $\mathrm{mol}^{-1}$ ); K120 - potassium application, $120 \mathrm{mg} \mathrm{L}^{-1}$; K240 potassium application, $240 \mathrm{mg} \mathrm{L}^{-1}$.

\begin{tabular}{lllllll}
\hline Treatment & \multicolumn{2}{l}{ Sink (Root)/ } & \multicolumn{4}{c}{ Flow (Stem)/ } \\
& \multicolumn{2}{l}{ Source (Leaf) } & \multirow{4}{l}{ Source (Leaf) } \\
& 9 & 25 & 43 & 9 & 25 & 43 \\
\hline EC-K120 & 0.0025 & 0.032 & 0.025 & 0.18 & 0.46 & 0.45 \\
EC-K240 & 0.093 & 0.14 & 0.15 & 0.23 & 0.57 & 0.64 \\
\hline
\end{tabular}

Table 4. Effects of $\mathrm{CO}_{2}$ and potassium supply on the ratio of soluble sugar for cucumber roots/leaves. $\mathrm{AC}-$ ambient $\mathrm{CO}_{2}$ concentration $\left(380 \mu \mathrm{mol} \mathrm{mol}^{-1}\right)$; $\mathrm{EC}$ - elevated $\mathrm{CO}_{2}$ concentration $\left(1,000 \mu \mathrm{mol} \mathrm{mol}^{-1}\right) ; \mathrm{K} 120$ - potassium application, $120 \mathrm{mg} \mathrm{L}^{-1}$; $\mathrm{K} 240$ - potassium application, $240 \mathrm{mg} \mathrm{L}^{-1}$.

Time [d] Root/leaf soluble sugar content ratio AC-K120 AC-K240 EC-K120 EC-K240

\begin{tabular}{lllll}
\hline 9 & 0.35 & 0.35 & 0.54 & 0.51 \\
25 & 0.42 & 0.46 & 0.55 & 0.71 \\
43 & 0.56 & 0.58 & 0.65 & 0.72 \\
\hline
\end{tabular}

Table 5. Effects of $\mathrm{CO}_{2}$ and potassium supply on the ratio of starch for cucumber roots/leaves. $\mathrm{AC}-$ ambient $\mathrm{CO}_{2}$ concentration $\left(380 \mu \mathrm{mol} \mathrm{mol}^{-1}\right)$; EC - elevated $\mathrm{CO}_{2}$ concentration $(1,000 \mu \mathrm{mol}$ $\mathrm{mol}^{-1}$ ); K120 - potassium application, $120 \mathrm{mg} \mathrm{L}^{-1}$; K240 potassium application, $240 \mathrm{mg} \mathrm{L}^{-1}$.

\begin{tabular}{lllll}
\hline Time [d] & \multicolumn{4}{l}{ Root/leaf starch content ratio } \\
& AC-K120 & AC-K240 & EC-K120 & EC-K240 \\
\hline 9 & 0.90 & 0.92 & 0.84 & 0.83 \\
25 & 1.14 & 0.78 & 0.69 & 0.66 \\
43 & 0.81 & 0.8 & 0.72 & 0.56 \\
\hline
\end{tabular}

Table 6. Correlation between net photosynthetic rate, glucose, and starch content in cucumber leaves. $\mathrm{AC}-$ ambient $\mathrm{CO}_{2}$ concentration $\left(380 \mu \mathrm{mol} \mathrm{mol}^{-1}\right)$; EC - elevated $\mathrm{CO}_{2}$ concentration $\left(1,000 \mu \mathrm{mol} \mathrm{mol}^{-1}\right) ; \mathrm{K} 120$ - potassium application, $120 \mathrm{mg} \mathrm{L}^{-1}$; K240 - potassium application, $240 \mathrm{mg} \mathrm{L}^{-1}$. * - significant correlation, $95 \%$ confidence level or $\alpha=0.05$ (two-tail). ** - highly significant correlation, 99\% confidence level or $\alpha=0.01$ (twotail).

\begin{tabular}{lll}
\hline Treatment & $P_{\mathrm{N}}$-soluble sugar & $P_{\mathrm{N}}$-starch \\
\hline AC-K120 & 0.489 & -0.753 \\
AC-K240 & 0.701 & -0.555 \\
EC-K120 & 0.758 & -0.612 \\
EC-K240 & $0.930^{* *}$ & $-0.983^{* *}$ \\
\hline
\end{tabular}

are limited. The present study showed that on 9 and $25 \mathrm{DAE}$, the $P_{\mathrm{N}}$ of plants periodically treated with $\mathrm{CO}_{2}$ at $1,000 \mu \mathrm{mol} \mathrm{mol}{ }^{-1}$ significantly increased compared to that of control plants under regular environmental conditions. However, on $43 \mathrm{DAE}$, the $P_{\mathrm{N}}$ of plants treated with
$1,000 \mu \mathrm{mol}\left(\mathrm{CO}_{2}\right) \mathrm{mol}^{-1}$ of was significantly lower than that of the control plants under regular environmental conditions. Our previous study showed that on $27 \mathrm{DAE}$, the $P_{\mathrm{N}}$ of plants treated with $\mathrm{CO}_{2}$ at $1,000 \mu \mathrm{mol} \mathrm{mol} \mathrm{m}^{-1}$ was the same as that of the control plants under regular environmental conditions (data not shown). Similar to the data in FACE conditions, our results showed that periodic administration of EC $\left(1,000 \mu \mathrm{mol} \mathrm{mol}{ }^{-1}\right)$ leads to photosynthetic acclimation. We also showed that an increase in potassium concentrations improves the photosynthetic rate. In addition, in each of the two $\mathrm{CO}_{2}$ concentrations, the elevated potassium content did not result in a significant increase of the photosynthetic rate on 9 DAE, although this was observed on 25 and 43 DAE. Thus, we concluded that high potassium content induced an increase in the photosynthetic rate of plants subjected to long-term high $\mathrm{CO}_{2}$ exposure, as well as alleviated photosynthetic acclimation.

Studies on FACE conditions have demonstrated that photosynthetic acclimation in wheat and rice is not due to stomatal limitation, namely, changes in stomatal conductance (Liao et al. 2002, 2003). However, other studies have shown that changes in $\mathrm{CO}_{2}$ concentrations affect stomatal conductance (Chen et al. 2011). Our data show that short-term $\mathrm{CO}_{2}$ enrichment (on days 9 and 25) did not affect $g_{\mathrm{s}}$, whereas an increase in potassium concentration enhanced $g_{\mathrm{s}}$ under two $\mathrm{CO}_{2}$ concentrations. However, long-term $\mathrm{CO}_{2}$ enrichment (on 43 DAE) significantly reduced $g_{s}$, whereas an increase in potassium content alleviated the decrease in $g_{\mathrm{s}}$. Thus, photosynthetic acclimation may be correlated with stomatal limitation, and potassium contents play a significant role in this particular process. This observation has also been validated through other $\mathrm{CO}_{2}$ fertilization experiments (Yuan et al. 2009).

Several studies have shown that increasing $\mathrm{CO}_{2}$ concentration improves the transport of photosynthetic products to the roots. Other studies have also demonstrated that $\mathrm{CO}_{2}$ concentration does not affect the allocation of photosynthetic products (Xu et al. 2007). In this study, we performed ${ }^{13} \mathrm{C}$ isotope tracing experiments at different time points after $\mathrm{CO}_{2}$ enrichment and investigated the allocation of photosynthetic products in cucumber plants exposed to different potassium concentrations. Our results demonstrated that elevated potassium contents significantly promoted the accumulation of photosynthetic products in different plant organs. At the three indicated time points $(9,25$, and $43 \mathrm{DAE})$, high potassium treatment significantly increased the abundance of photosynthetic assimilative $\mathrm{C}\left(\delta^{13} \mathrm{C}\right)$ in the roots, stems, and leaves, in which the increase in the abundance in the roots was significant. This suggested that the elevation in potassium increases transport of photosynthetic products from the leaves (source) to the roots (sink). The elevated potassium concentrations ensured the transport of photosynthetic products from the source to the sink, particularly on 43 DAE, when the photosynthetic acclimation occurred. This indicates that increasing potassium under $\mathrm{CO}_{2}$ enrichment conditions promotes the transport of photosynthetic products, which allocates the photosynthetic products to different plant organs and consequently alleviates 
photosynthetic acclimation. This is also validated by the observed photosynthetic assimilative $\mathrm{C}\left(\delta^{13} \mathrm{C}\right)$ sink (roots)/ source (leaves) and flow (stems)/source (leaves) ratios. At the three indicated time points, both the sink/source and flow/source ratios increased when potassium increased under the $\mathrm{CO}_{2}$ enrichment conditions. This demonstrated that elevating potassium contents under $\mathrm{CO}_{2}$ enrichment conditions promotes the transport of photosynthetic products from the source (leaf) to the flow (stem) and the sink (root) of cucumber plants.

In plants, massive starch accumulation in leaves leads to a pressure gradient between leaves and roots, which in turn promote soluble carbohydrate transport (Suter et al. 2002, Xu et al. 2007). The root (sink)/leaf (source) soluble carbohydrates content ratio of plants treated with $\mathrm{AC}$ and $\mathrm{K} 120$ was lower than those treated under the other conditions. Particularly, on 43 DAE, the root (sink)/leaf (source) soluble carbohydrates content ratio of plants treated with EC and K240 was the highest. This suggests that high potassium treatment promotes the transport of photosynthetic products from the leaves (source) to the roots (sink). The root/leaf starch content ratio of plants treated with regular $\mathrm{CO}_{2}$ and potassium contents was higher than those in the other conditions, which is opposite that observed in the root/leaf soluble carbohydrates content ratio described earlier. Thus, $\mathrm{CO}_{2}$ enrichment and potassium enhancement promoted photosynthesis, starch accumulation, and the allocation of soluble carbohydrates.

In this study, the net photosynthetic rates of plants treated with all four conditions were negatively correlated with the corresponding starch contents. In particular, the net photosynthetic rate of plants treated with high potassium and high $\mathrm{CO}_{2}$ was highly significantly and negatively correlated with the starch content. This suggests that longterm $\mathrm{CO}_{2}$ enrichment leads to massive starch accumulation in the leaves, which in turn impairs photosynthesis and reduces net photosynthesis. However, potassium elevation increases starch accumulation, enhances the osmotic pressure between source and sink, and promotes the transport of photosynthetic products from the source to the sink. The root/leaf soluble carbohydrates content ratio of plants treated with regular $\mathrm{CO}_{2}$ and regular potassium concentrations was lower than that for plants subjected to the other conditions. In addition, on days 25 and 43 of $\mathrm{CO}_{2}$ enrichment, the root/leaf soluble carbohydrate content ratio of plants treated with high $\mathrm{CO}_{2}$ and high potassium was the highest. Our data suggest that high potassium contents under $\mathrm{CO}_{2}$ enrichment conditions promote the transport of photosynthetic products from the leaves (source) to the roots (sink).

\section{References}

Agüera E., Ruano D., Cabello P. et al.: Impact of atmospheric $\mathrm{CO}_{2}$ on growth, photosynthesis and nitrogen metabolism in cucumber (Cucumis sativus L.) plants. - J. Plant Physiol. 163: 809-817, 2006.

Chen H., Dickinson R.E., Dai Y. et al.: Sensitivity of simulated terrestrial carbon assimilation and canopy transpiration to different stomatal conductance and carbon assimilation schemes. - Clim. Dynam. 36: 1037-1054, 2011.

Delucia E., Sasek T.W., Strain B.R.: Photosynthetic inhibition after long term exposure to elevated levels of atmospheric carbon dioxide. - Photosynth. Res. 7: 175-184, 1985.

Kimball B.A., Kobayashi K., Bindi M.: Responses of agricultural crops to free-air $\mathrm{CO}_{2}$ enrichment. - Adv. Agron. 77: 293-368, 2002.

Long S.P, Ainsworth E.A, Rogers A. et al.: Rising atmospheric carbon dioxide: Plants FACE the future. - Annu. Rev. Plant Biol. 55: 591-628, 2004.

Maggio A, Dalton F.N., Piccinni G.: The efects of elevated carbon dioxide on static and dynamic indices for tomato salt tolerance. - Eur. J. Agron. 16: 197-206, 2002.

Liao Y., Chen G.Y., Zhang D.Y.: [Non-stomatal acclimation of leaf photosynthesis to free-air $\mathrm{CO}_{2}$ Enrichment (FACE) in winter wheat.] - J. Plant Phys. 29: 494-500, 2003. [In Chinese]

Liao Y., Chen G.Y., Zhang H.B.: [Response and acclimation of photosynthesis in rice leaves to free-air $\mathrm{CO}_{2}$ enrichment (FACE).] - Chin. J. Appl. Ecol. 13: 1205-1209, 2002. [In Chinese]

Lin B.Y., Zhang Y., Lin Y.Z. et al.: [Effects of $\mathrm{CO}_{2}$ concentration on photosynthetic characteristic and physiological and biochemical indices of cowpea.] - Plant Nutr. Fertil. Sci. 17: 964 -969, 2011. [In Chinese]

Qi H.Y., Li T.L., Zhang J. et al.: [Relationship between carbohydrate change and related enzymes activities during tomato fruit development.] - Acta Hortic. Sin. 33: 294-299, 2006. [In Chinese]

Reddy K.R., Zhao D.L.: Interactive efects of elevated $\mathrm{CO}_{2}$ and potassium deficiency on photosynthesis, growth, and biomass partitioning of cotton. - Field Crop. Res. 94: 201-213, 2005.

Suter D., Frehner M., Fischer B.U.: Elevated $\mathrm{CO}_{2}$ increases carbon allocation to the roots of Lolium perenne under free-air $\mathrm{CO}_{2}$ enrichment but not in a controlled environment. - New Phytol. 154: 65-75, 2002.

Xu Z.Z, Zhou G.S, Wang Y.H.: Combined effects of elevated $\mathrm{CO}_{2}$ and soil drought on carbon and nitrogen allocation of the desert shrub Caragana intennedia. - Plant Soil 301: 87-97, 2007.

Yin Y.F., Yang Y.S., Gao R. et al.: [A preliminary study on phytoenrichment ${ }^{13} \mathrm{C}$ labeling technique.] - Acta Pedol. Sin. 47: 790-793, 2010. [In Chinese]

Yu X.J.: [Plant Physiology Laboratory Manual.] Pp. 148-149. Shanghai Sci. Technol. Press., Shanghai 1985. [In Chinese]

Yuan H.M., Zhou J.M., Duan Z.Q. et al.: [Effects of elevated $\mathrm{CO}_{2}$ and potassium on cucumber growth.] - Soils 41: 869874, 2009. [In Chinese]

(C) The authors. This is an open access article distributed under the terms of the Creative Commons BY-NC-ND Licence. 